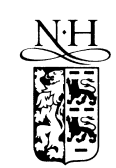

ELSEVIER
Journal of Economic Psychology 20 (1999) 521-546

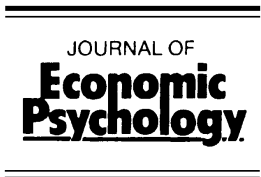

www.elsevier.com/locate/joep

\title{
A review and meta-analysis of country-of-origin research
}

\author{
Peeter W.J. Verlegh ${ }^{\text {a,* }}$, Jan-Benedict E.M. Steenkamp a,b \\ ${ }^{a}$ Wageningen University, Marketing and Consumer Behaviour Group, Hollandseweg 1, \\ 6706 KN Wageningen, The Netherlands \\ ${ }^{\mathrm{b}}$ Tilburg University, Department of Marketing, P.O. Box 90153, 5000 LE Tilburg, The Netherlands
}

Received 7 February 1998; accepted 12 June 1999

\begin{abstract}
Despite a large body of research, country-of-origin effects are still poorly understood. Combining the strengths of a narrative review with those of a quantitative meta-analysis, our study seeks to establish a firm grounding for country-of-origin research. We review previous country-of-origin research, focusing on cognitive, affective, and normative aspects of country of origin. In a quantitative meta-analysis, we assess the magnitude of country-of-origin effects on three types of product evaluations, viz., perceived quality, attitude, and purchase intention. In addition, we develop and test hypotheses concerning the role of economic development, the impact of multi-national production, differences between consumers and industrial purchasers, and a number of methodological aspects. We find that country of origin has a larger effect on perceived quality than on attitude toward the product or purchase intention. We also find that differences in economic development are an important factor underlying the country-of-origin effect. The country-of-origin effect does not differ between industrial and consumer purchasing, nor is it affected by multi-national production. We conclude with suggestions for future research on the country-of-origin effect. Specifically, more research is needed on the symbolic and emotional aspects of country of origin, and on the role of competitive context. (C) 1999 Elsevier Science B.V. All rights reserved.
\end{abstract}

PsycINFO classification: 3900

\footnotetext{
${ }^{*}$ Corresponding author. Tel.: +31-317-482201; fax: +31-317-484361; e-mail: peeter.verlegh@alg. menm.wau.nl
} 
JEL classification: M30

Keywords: Meta-analysis; Consumer psychology

\section{Introduction}

Consumers are constantly confronted with a wide variety of product information, supplied through packaging, branding, advertising and other channels. This information is used by consumers to form preferences and purchase decisions, but it also elicits emotions, feelings, imagery, and fantasies. The present study focuses on the product's country of origin, an aspect of product information with a complex effect on consumer behavior (cf., Papadopoulos \& Heslop, 1993; Askegaard \& Ger, 1998). Dichter (1962) was the first to argue that a product's country of origin may have a "tremendous influence on the acceptance and success of products" (p. 116). The first empirical test of this notion was conducted by Schooler (1965). He found significant differences in the evaluation of products that were identical in all respects, except for the name of the country specified on a "made in" label. Since Schooler's seminal paper, the "country-of-origin effect" has been the subject of a large number of studies. Most of these studies have focused on assessing the occurrence, magnitude and significance of country-of-origin effects for different products. In spite of a large body of research, consensus with regard to the importance of the effect has not been reached. Obermiller (1993) observed that the substantial differences in effect sizes most likely stem from differences in study characteristics. In an attempt to synthesize the literature on the country-of-origin effect, Peterson and Jolibert (1995) showed that country of origin has a strong influence on product evaluation. They also found that the size of the effect is significantly affected by a number of study characteristics. Their findings lead them to conclude that "country-of-origin effects are only somewhat generalizable" and that "the phenomenon is still not well understood" (Peterson \& Jolibert, 1995, pp. 894-895).

In the present study, we attempt to achieve a better understanding of the role of country of origin in consumer behavior. We go beyond effect sizes, and search for explanations for the country-of-origin effect. We will start with a review of the theoretical developments in country-of-origin research. Then, we develop a set of hypotheses concerning the impact of various methodological and conceptual factors on country-of-origin effects. These hypotheses are tested in a meta-analysis, that allows us to derive generalized 
explanations for country-of-origin effects, that can be regarded as "the building blocks" of scientific advance in this domain (cf., Bass \& Wind, 1995)

\section{The role of country of origin in consumer product evaluation}

Country-of-origin research has mainly studied the use of country of origin as a cognitive cue, viz., an informational stimulus about or relating to a product that is used by consumers to infer beliefs regarding product attributes such as quality (Bilkey \& Nes, 1982; Steenkamp, 1990). Since country of origin can be manipulated without changing the physical product, it is regarded as an extrinsic cue (Olson, 1972). In this respect, country of origin is not different from other extrinsic cues like price, brand name and retailer reputation. A large number of studies has shown that such cues act as "signals" for product quality (e.g., Steenkamp, 1990; Dawar \& Parker, 1994). The typical design of such studies is to describe a product on a number of attributes (cues) and assess the impact of country of origin and the other cues on the overall evaluation of the product.

Various studies, however, have shown that country of origin is not merely another cognitive cue. Wyer and colleagues (Hong \& Wyer, 1989, 1990; Li \& Wyer, 1994) showed that the impact of country of origin cannot be explained entirely by a quality signaling process. In addition to its role as a quality cue, country of origin has symbolic and emotional meaning to consumers. Country of origin may associate a product with status, authenticity and exoticness (Li \& Monroe, 1992; Batra, Ramaswamy, Alden, Steenkamp \& Ramachander, 1999) Moreover, it links a product to a rich product-country imagery, with sensory, affective and ritual connotations (Askegaard \& Ger, 1998). Fournier (1998) found that country of origin relates a product to national identity, which can result in a strong emotional attachment to certain brands and products. She describes the case of a second-generation Italian-American woman who is strongly attached to Italian products, especially food-related items. For this person, "Italy" has very strong emotional and symbolic connotations. Botschen and Hemettsberger (1998) reported that consumers link country of origin not only to product quality, but also to feelings of national pride and memories of past vacations.

These studies indicate that country of origin is not merely a cognitive cue for product quality, but also relates to emotions, identity, pride and autobiographical memories. Such symbolic and emotional connotations transform country of origin into an "expressive" or "image" attribute 
(cf., Lefkoff-Hagius \& Mason, 1993). Such attributes have been shown to be significant determinants of consumer preferences and an important source of brand equity (Lefkoff-Hagius \& Mason, 1993).

Obermiller and Spangenberg (1989) developed a framework that will be used to structure our discussion of the various ways in which country of origin influences consumer product evaluations. The framework distinguishes between cognitive, affective and normative processing of the country-of-origin cue. It should be noted that the boundaries between these processes are fuzzy, and cognitive, affective and normative processes are interacting in consumer decision-making (Isen, 1984). Nevertheless, this framework is broadly consistent with the majority of the country-of-origin literature, and best structures our review of current knowledge on country-of-origin effects. Below, we will first discuss cognitive, affective and normative aspects of country-of-origin effects separately. Next, we elaborate on interactions of cognitive, affective and normative aspects of country of origin. Table 1 provides examples of cognitive, affective and normative mechanisms for country-of-origin effects.

\subsection{Cognitive aspects of the country-of-origin effect}

Information processing models of consumer decision making generally assume that judgments of product quality are inferred from cues (Steenkamp, 1989; Dawar \& Parker, 1994). Provided that basic criteria for cue selection,

Table 1

Examples of cognitive, affective and normative mechanisms for country-of-origin effects

\begin{tabular}{|c|c|c|}
\hline Mechanism & Description & Major findings \\
\hline Cognitive & $\begin{array}{l}\text { Country of origin is a cue } \\
\text { for product quality }\end{array}$ & $\begin{array}{l}\text { Country of origin is used as a "signal" for overall } \\
\text { product quality and quality attributes, such as } \\
\text { reliability and durability (Li \& Wyer, 1994; Steen- } \\
\text { kamp, 1989). }\end{array}$ \\
\hline Affective & $\begin{array}{l}\text { Country of origin has symbolic } \\
\text { and emotional } \\
\text { value to consumers }\end{array}$ & $\begin{array}{l}\text { Country of origin is an image attribute that links the } \\
\text { product to symbolic and emotional benefits, includ- } \\
\text { ing social status and national pride (Askegaard \& } \\
\text { Ger 1998; Batra et al., 1998). }\end{array}$ \\
\hline Normative & $\begin{array}{l}\text { Consumers hold social } \\
\text { and personal norms related } \\
\text { to country of origin }\end{array}$ & $\begin{array}{l}\text { Purchasing domestic products may be regarded as a } \\
\text { "right way of conduct", because it supports the } \\
\text { domestic economy (Shimp \& Sharma, 1987). By the } \\
\text { same token, consumers may refrain from buying } \\
\text { goods from countries with objectionable activities or } \\
\text { regimes (Smith, 1990; Klein, Ettenson \& Morris, } \\
\text { 1998)). }\end{array}$ \\
\hline
\end{tabular}


like vividness, clarity, and intensity are met, the use of a cue is determined by consumers' perception of its predictive value. The latter refers to the perceived strength of the relationship between a cue and the attribute that is to be judged (Olson, 1972; Steenkamp, 1989). The predictive value of a cue is affected by (1) the "ecological" or "observed" covariation between cue and attribute (Steenkamp, 1989), and (2) the perceived theoretical or intuitive relationship between cue and attribute (Pinson, 1986; Broniarczyk \& Alba, 1994). In the case of country of origin, this theoretical relationship is largely shaped by product-country images, which are mental representations of a country's people, products, culture and national symbols (Ger, 1991; Askegaard \& Ger, 1996, 1998). Product-country images contain widely shared cultural stereotypes. For example, Leclerc, Schmitt and Dubé (1994) found a positive effect of French-sounding brand names on evaluations of "hedonic" products such as perfume and wine, but a negative effect on the evaluations of "utilitarian" products like cars and computers. These effects persisted even when subjects actually experienced the product. Product-country images also contain general impressions of countries and idiosyncratic beliefs about a country's products, which consumers have formed in direct or indirect product experiences.

The finding that product evaluations relate to a number of characteristics of the origin country emphasizes the role of general impressions of countries in the country-of-origin effect (Bilkey \& Nes, 1982). For example, consumers recognize that the production of high-quality technical products requires a highly trained and educated workforce. Hence, they perceive that such products are of better quality when produced in developed countries. The improvement in the quality image of Japanese products, however, shows that such beliefs can change over time, and also depend on direct experiences of the quality of a country's products.

Roth and Romeo (1992) formulated a theoretical framework for the relationship between consumer preferences for a country's products, and perceptions of a country's culture, economy and politics. They argued that consumers' evaluations of a specific product from country $X$ are based on the match between product and country. According to these authors, consumers prefer country $X$ as an origin for specific products when they belief that there is a match between the perceived "strengths" of country $X$ and the skills that are needed for manufacturing the product under consideration. A preference for German cars, for example, might be explained by the perception of the workmanship of German engineers, and the fact that Germany is a technologically advanced society. 


\subsection{Affective aspects of the country-of-origin effect}

As mentioned earlier, country-of-origin effects cannot be attributed solely to the signaling of product quality. Countries have strong emotional and affective connotations, that may be formed in direct experiences during holidays or encounters with foreigners, but also in indirect experiences with countries and their citizens through, e.g., art, education and mass media. Such connotations may influence consumers' product or brand attitudes. Obermiller and Spangenberg (1989) use the example of an Arab-American who recognizes the superior quality of Israeli optical instruments, but nevertheless has a negative attitude toward these products, that is caused by a strong negative attitude toward Israel. They note, however, that such a mechanism is limited to specific cases, where the attitude toward a country is very strong.

Such a perspective, however, reflects a rather narrow view of the impact of affective associations on the evaluation of countries and their products. Consumers link country of origin to autobiographical memories, to national or ethnic identities and to feelings of "status" and "pride" associated with the possession of products from certain countries (Hirschman, 1985; Batra et al., 1999; Botschen \& Hemettsberger, 1998; Fournier, 1998). It seems clear, therefore, that country of origin also acts as an "expressive" or "image" attribute. Expressive motives "would embrace esteem, social and self-actualization needs..." (Mittal, Ratchford \& Prabhakar, 1990, p. 138). Image attributes "reveal how product use and/or ownership associates the consumer with a group, role or self-image" (Lefkoff-Hagius \& Mason, 1993, p. 101). A noteworthy example of the latter is provided by Batra et al. (1999) who found that in India, a "western" product origin has a substantial positive effect on brand attitudes, even after controlling for perceived quality. The symbolic and social dimension of this phenomenon was further emphasized by the finding that this effect was most powerful for consumers with a high admiration for "western" lifestyles, and for products of which the consumption and ownership are more publicly visible. Similar findings have been reported in a number of anthropological studies in Nigeria (Arnould, 1989), Romania and Turkey (Ger, Belk \& Lascu, 1993).

\subsection{Normative aspects of the country-of-origin effect}

Because purchasing a country's products is a way of supporting its economy, the purchase of products from countries that engage in objectionable 
activities can be regarded as an a-moral action. Smith (1990) coined the term "customer voting" to capture this phenomenon: by deciding to purchase or avoid a country's products consumers "vote" pro or contra the policies and practices of its government. Such behavior can be found throughout the world, with for example Jewish consumers boycotting German products because of the holocaust and Australian consumers having boycotted French products because of French nuclear tests in the Pacific. Recently, Klein et al. (1998) found that Chinese consumers' willingness to buy Japanese products is affected by the economic and military rivalry between the two countries. The purchase of Japanese products is perceived by some Chinese consumers to be equivalent to treason. There are also instances where consumers reward "sympathetic" countries or regimes through the purchase of their products. Friedman (1996) calls these "buycotts".

Another salient norm that relates to country of origin is the norm to buy domestic. Many consumers consider it morally appropriate to buy products that are manufactured or grown in their own country (Shimp \& Sharma, 1987). In countries such as the US, Canada and the UK, governments, labor unions, and industry groups have been sponsoring campaigns aimed at the establishment of a "buy domestic" norm. Consumer ethnocentrism (Shimp \& Sharma, 1987) serves as an important motivation for the decision to purchase domestic products. It refers to consumers' judgments of the morality of purchasing foreign made products. Consumer ethnocentrism has been found to relate positively to consumer preference for domestic products, and negatively to preference for foreign products (Shimp \& Sharma, 1987). This indicates that the perceived morality of purchasing foreign (vs. domestic) products indeed has a substantial impact on consumers' product attitudes.

\subsection{The interplay of cognitive, affective and normative aspects of country of origin}

In reality, cognitive, affective and normative processes are not separate and independent determinants of preferences and behaviors. They are constantly interacting. As noted by Hoffman (1986), affect provides a motivating force for information processing, and may initiate, terminate or enhance the processing of information. Affective responses to country of origin may thus stimulate or inhibit further consideration of choice alternatives, and influence the retrieval and evaluation of cognitive beliefs related to the country of origin (Isen, 1984; Ger, 1991; Askegaard \& Ger, 1998). Positive affect leads to more extensive and more diverse mental representations (Isen, 1984). 
Affect has also been found to influence the amount of information that is used to make a decision, and the strategy that is followed to combine this information and arrive at a decision (Cohen \& Areni, 1991). Affect thus plays an important role in determining which beliefs are formed, how they are evaluated, and how strongly they are weighted in the formation of preferences.

Normative judgments related to the purchase of a country's products involve both cognitive and affective responses as well. The complex issues that are at stake in boycotts and buycotts require elaborate cognitive processing, but also evoke emotions like fear and anger (Osterhus, 1997; Klein et al., 1998). Schwartz (1973) even argued that the impact of personal norms on behavior and decision making is largely based on the fact that a violation of norms results in feelings of guilt and loss of self-esteem, while conformity results in pride and enhanced self-esteem. Consumer ethnocentrism includes affective elements like "a sense of identity" and "feelings of belongingness" (Shimp \& Sharma, 1987, p. 280). Its effect on preference formation is moderated by cognitive beliefs that consumers have about the extent to which their country or their own job is threatened by foreign competition (Sharma, Shimp \& Shin, 1995).

\section{Empirical generalizations in country-of-origin research}

Having discussed the different mechanisms that play a role in country-oforigin effects, we now turn to a quantitative integration of country-of-origin research, using meta-analysis. Meta-analysis enables us to determine the robustness of empirical findings on country-of-origin effects. Moreover, it allows us to examine the extent to which the magnitude of country-of-origin effects is affected by study characteristics (Farley, Lehmann \& Sawyer, 1995).

\subsection{Meta-analysis and the parametric adjustability model}

The studies that investigate country-of-origin effects apply a variety of research designs and study different products from different countries. At the same time, however, they are all aimed at assessing the same phenomenon, viz., the influence of country-of-origin on product evaluations. Such a body of research can be seen as a set of imperfect replications. The individual studies are replications in the sense that they investigate the same effect, but the replications are imperfect, since they differ from each other on a number of factors. As Farley and Lehmann (1994) and Farley et al. (1995) point out, 
the fact that the studies are imperfect replications allows us to draw conclusions that cannot be drawn from a set of exact replications or from single studies. Specifically, the fact that studies that examine the same effect differ in various ways allows us to determine the way in which these differences influence the size of the country-of-origin effect. For this, Farley and Lehmann (1994) proposed the method of "parametric adjustability".

This method consists of three consecutive steps. First, the researcher collects empirical studies that investigate the same phenomenon. The next step involves the identification of study characteristics that are expected to cause systematic differences in the results of individual studies. Third, the model is analyzed by regression analysis using dummy variables.

\subsubsection{Sampling studies}

Empirical studies of country-of-origin effects, appearing in marketing and business literature in the period of 1980-1996 were identified through issueby-issue searches of a large number of journals that publish marketing and business research (Columbia Journal of World Business, European Journal of Marketing, International Journal of Research in Marketing, Journal of Business Research, Journal of Consumer Psychology, Journal of Consumer Research, Journal of Economic Psychology, Journal of International Business Studies, Journal of Marketing, Journal of Marketing Research, Journal of Retailing, Journal of the Academy of Marketing Science, Marketing Letters and Marketing Science) and proceedings of ACR, AMA and EMAC conferences. This search was backed-up by means of a computer bibliographic search using the ABI Inform system.

\subsubsection{Effect size indicator}

To enable a comparison of the size of the country-of-origin effects reported in different studies, these effects were converted into a common measure of effect size. Such a measure is an estimate of the degree to which the relationship of interest is present in a population. We selected Pearson's productmoment correlation coefficient, as it is the most widely used measure of effect size, that can be derived from a large number of summary statistics by means of relatively simple formulas (Fern \& Monroe, 1996).

\subsection{Study characteristics}

Following the retrieval of a large number of effect sizes, the next step is the selection of study characteristics likely to moderate the country-of-origin 
effect. From our review of country-of-origin literature, we have identified several variables that may have an impact on country-of-origin effect sizes. In addition, we have incorporated several variables that relate to aspects of research design.

\subsubsection{The magnitude of country-of-origin effects on various types of product evaluations}

In a typical study of country-of-origin effects, consumers are asked to form an overall evaluation of a product alternative that is described verbally by a number of cues, including country of origin. By including the "dependent measure" as a moderator variable in the parametric adjustability model, we can establish the impact of country of origin on the different types of judgments used in such research. Specifically, we distinguish between measures of perceived quality (including ratings of "performance" and "reliability"), product attitudes, and purchase intentions.

Judgments regarding perceived quality and attitude (and purchase intentions) can be formed independent of each other. However, there is conceptual support for the notion that perceived quality is a key component of attitude (Holbrook \& Corfman, 1985; Steenkamp, 1989). For example, Holbrook and Corfman (1985) found that the overall attitude toward a product was affected by perceived quality, but also by convenience, fun and beauty. Thus, the attitude concept is "broader" than the quality construct, encompassing more and different factors. This should reduce the effect of country of origin. Moreover, the design of the typical country-of-origin study is more suited to study cognitive rather than affective processes. Since perceived quality has stronger cognitive overtones than attitude (Obermiller \& Spangenberg, 1989; Steenkamp, 1989, see also Holbrook \& Corfman, 1985), one may expect greater country-of-origin effects for perceived quality than for attitudes and intentions.

Purchase intentions do not only represent a trade off between consumer needs and product features, but also incorporate several "external" influences, of which budget constraints are the most important. Specifically, consumers may perceive a product to be of high quality, and like it very much, but they may simply not be able to afford it. Hence, the impact of country-related inferences should be smallest for purchase intentions. We therefore hypothesize that:

H1. The effect of country of origin is largest for perceived quality (attributes), and smallest for purchase intentions, with attitude judgments falling in between. 


\subsubsection{Characteristics related to the product}

Another issue that deserves attention is the generalizability of country-oforigin effects across different types of products. Although country-of-origin effects have been studied most frequently for consumer products, several studies have investigated the phenomenon for industrial products (cf., Bilkey $\&$ Nes, 1982). In general, purchasing agents are viewed as being more rational and better informed than household buyers (Webster \& Wind, 1972). It seems likely that they are less influenced by extrinsic product information, such as country of origin. Although direct comparisons of country-of-origin effects in industrial and household buying are scarce, Ahmed and d'Astous (1995) suggest that industrial buyers may indeed be less susceptible to country information. We hypothesize therefore, that:

H2. The country-of-origin effect is larger for consumer goods than for industrial goods.

The term "country of origin" implies that products are (at least for the largest part) produced in a single country. In the "global era", however, manufacturers are spreading out their activities over a larger number of countries, which gives rise to multi-national production (Yip, 1995). In light of this, Chao (1993) distinguishes between hybrid and non-hybrid products, the former being those products that are designed/branded in one country and manufactured in another (e.g., Volkswagen manufactured in Brazil). In a typical experiment involving hybrid products, "country of manufacture" is manipulated independently from "country of design". On one hand, it may be argued that consumers are aware of international sourcing practices, and that a specification of the country of manufacture increases the informational value of the country-of-origin cue, and thus its impact on product evaluations. On the other hand, separating country of origin into country of design and country of manufacture may result in a decrease of the meaning that consumers attach to these constructs. Hence, it seems worthwhile to explore how "country-of-origin" effect sizes are affected by multinational production.

H3. The magnitude of the country-of-origin effect differs between hybrid and non-hybrid products

As pointed out in our literature review, product evaluations based on country-of-origin information are often related to consumers' beliefs regarding general characteristics of the country of origin. One of these char- 
acteristics is the country's level of development. As noted by Porter (1990), the ability to manufacture products that require a certain level of skill and technology is closely related to a country's level of development. Consequently, the mere fact that a product is made in a less-developed country suggests to (western) consumers that it is of poorer quality, and associated with an increased risk of bad performance and dissatisfaction (Cordell, 1991). Hence, products from Less Developed Countries (LDCs) are generally evaluated less positively than products from More Developed Countries (MDCs) (Bilkey \& Nes, 1982). Thus, we expect to find larger country-oforigin effects when products from MDCs and LDCs are included in the same study, and smaller effects when a study exclusively examines products from either MDCs or LDCs. For purposes of objectivity and convenience, we chose to define MDCs as all OECD-member countries, excluding those designated by the OECD as "developing" (viz., Greece, Mexico and Turkey). We hypothesize that:

H4. The country-of-origin effect is larger in studies that compare products from MDCs to products from LDCs, than in studies that compare products from either MDCs or LDCs.

\subsubsection{Characteristics related to research design}

Bilkey and Nes (1982) noted a number of serious methodological shortcomings in country-of-origin research. Their review and suggestions for improvements received wide attention in the literature, but methodological issues have remained a source of concern (e.g., Usunier, 1996). To investigate whether the alleged methodological shortcomings affect the magnitude of country-of-origin effects reported in the literature, we will analyze a number of characteristics related to the design of country-of-origin research.

A first issue concerns the use of single-cue vs. multi-cue designs. Early studies of the country-of-origin effect often used a so-called single-cue design, in which subjects are presented only with information about the product's country of origin, and are asked to provide a product evaluation. Such studies have often been criticized for their lack of realism and inflation of effect sizes (Bilkey \& Nes, 1982; Steenkamp, 1989). It is obvious that consumers infer product quality from country of origin, when it is the only information available. Hence, we hypothesize that:

H5. The country-of-origin effect is smaller in multi-cue studies than in singlecue studies. 
Another important distinction is between within-subjects and betweensubjects designs. In a within-subjects design, subjects are asked to provide judgments for multiple products, from different countries of origin. This procedure may lead to respondents "discovering" the purpose of the study, and they may try to answer in a way that they think pleases the experimenter (i.e., demand artifacts). Moreover, presenting the same respondent with several product descriptions that vary on a limited number of attributes may lead to sensitization to the manipulated attributes. Consequently, the respondent will devote more attention to these attributes, and their effects will be inflated. These effects are less likely to occur in between-subjects designs (Fern \& Monroe, 1996). Furthermore, the error term in between-subjects designs includes random variation due to individual differences, which leads to smaller effect size estimates. Taken together, these processes are likely to result in increased effect sizes for within-subjects designs (Rao \& Monroe, 1989):

H6. Within-subjects designs yield larger effect sizes than between-subjects designs.

The question whether student samples are representative of "real consumers" has raised considerable debate in marketing and consumer research (e.g., Sternthal, Tybout \& Calderet, 1994). Student samples differ from general consumer samples on two important aspects. First, they are different in socio-demographics. Students are younger and higher educated than the average consumer. It has been shown that country-of-origin effects are generally smaller for younger consumers and for consumers with a higher level of education (Usunier, 1996). Second, student samples are more homogeneous than consumer samples. Consequently, student samples might yield larger effects because they have lower response variance due to individual differences (Sternthal et al., 1994). These biases go in opposite directions. On one hand, student samples are expected to yield smaller effect sizes than representative consumer samples. On the other hand, student samples are expected to yield larger effect sizes. Hence, we hypothesize:

H7. The magnitude of the country-of-origin effect does not differ between studies that use student samples and studies that use "representative" consumer samples. 


\subsection{Analysis}

To investigate the influence of moderator variables on effect sizes, a twostep procedure is generally recommended (Hedges \& Olkin, 1985; Farley et al., 1995). After the average effect size has been calculated and found to be significant, a (chi-square) test for homogeneity is conducted. If this test indicates that effect sizes are homogeneous across studies, variation in effect size is due to random error, and no further analyses on its sources are warranted. On the other hand, heterogeneity in effect sizes indicates that at least part of the variability is systematic (Hedges \& Olkin, 1985).

When the effect sizes are heterogeneous, their variance can be examined through the application of the parametric adjustability model (Farley et al., 1995). Here, the impact of moderator variables is analyzed through dummy regression analysis, with the effect size as dependent variable and $j$ dummy variables representing the various study characteristics as independent variables. If the effect sizes are correlation coefficients, the data are usually $z$ transformed, to achieve normality (Hedges \& Olkin, 1985). In formula:

$$
z_{i}=b_{0}+\sum_{i} b_{j} C_{i j}+u_{i},
$$

where $z_{i}$ is a $z$-transformed effect size $i, C_{i j}(j=1, \ldots, k)$ are $k$ moderator variables, $b_{j}$ 's are regression coefficients and $u_{i}$ is a random error term. A complete listing of moderator variables is included in Table 2.

Because the variance of effect size estimates is inversely proportional to sample size, the parametric adjustability model is estimated through a weighted least-squares procedure with $n-3$ as weight (Hedges \& Olkin, 1985). Furthermore, since most studies yield more than one effect size, the observations that are used to estimate the model cannot be regarded as independent. A general solution for this problem is the addition of a dummy variable for each study, except for one, which then serves as a baseline (Johnston, 1984). In meta-analysis, however, this is likely to result in severe multicollinearity. To avoid this problem, we included only the most relevant study dummies, selected through a procedure introduced by Anderson and Weitz (1989). First, the model was estimated without the study dummies. The residuals from this analysis were used as the dependent variable in a new (stepwise) regression analysis with the study dummies as independent variables. The dummies that were included in the stepwise model were added to the original model, which was then re-estimated. 
Table 2

List of moderator variables included in the parametric adjustability model

\begin{tabular}{|c|c|c|}
\hline Moderator & Levels & Hypothesis \\
\hline Quality & $\begin{array}{l}0=\text { attitudinal measures } \\
1=\text { perceived quality }\end{array}$ & $\mathrm{H} 1:+$ \\
\hline Intentions & $\begin{array}{l}0=\text { attitudinal measures } \\
1=\text { purchase intentions }\end{array}$ & H1: - \\
\hline Product type & $\begin{array}{l}0=\text { industrial goods } \\
1=\text { consumer goods }\end{array}$ & $\mathrm{H} 2:+$ \\
\hline Hybrids & $\begin{array}{l}0=\text { uninational products } \\
1=\text { hybrid products }\end{array}$ & H3: ? \\
\hline Development & $\begin{array}{l}0=\text { products from MDCs compared to } \\
\text { products from other MDCs } \\
1=\text { products from MDCs compared to } \\
\text { products from LDCs }\end{array}$ & H4: + \\
\hline No. of cues & $\begin{array}{l}0=\text { single-cue design } \\
1=\text { multi-cue design }\end{array}$ & H5: - \\
\hline Design & $\begin{array}{l}0=\text { within-subjects design } \\
1=\text { between-subjects design }\end{array}$ & H6: - \\
\hline Sample type & $\begin{array}{l}0=\text { "representative" consumer sample } \\
1=\text { student sample }\end{array}$ & $\mathrm{H} 7: 0$ \\
\hline
\end{tabular}

\section{Results}

Our search procedure yielded 41 empirical studies, which are listed in the Appendix. A total number of 278 individual effect sizes was retrieved. To establish the mean of these values, the weighted (by $n-3$ ) average of the $z$ transformed effect sizes was calculated and then converted back to $r$. This yielded an average $r$ of 0.39 , which may be classified as a medium to large effect (cf., Cohen, 1988). The distribution of $r$ 's is displayed in Fig. 1, which contains a stem-and-leaf plot of the individual effect sizes.

The null hypothesis of homogeneity was rejected $\left(\chi^{2}(277)=2315.43\right.$, $p<0.001$ ), implying that the variance in effect sizes may be attributed (partly) to the influence of moderator variables. This influence was investigated with the model specified in (1). Eleven study dummies were selected through the earlier described procedure, and added to the original model. Our final model explained a significant portion of the variance in effect sizes $\left(R^{2}=0.438\right.$, $p<0.001)$. Parameter estimates and summary statistics for the parametric adjustability model are given in Table 3 . 


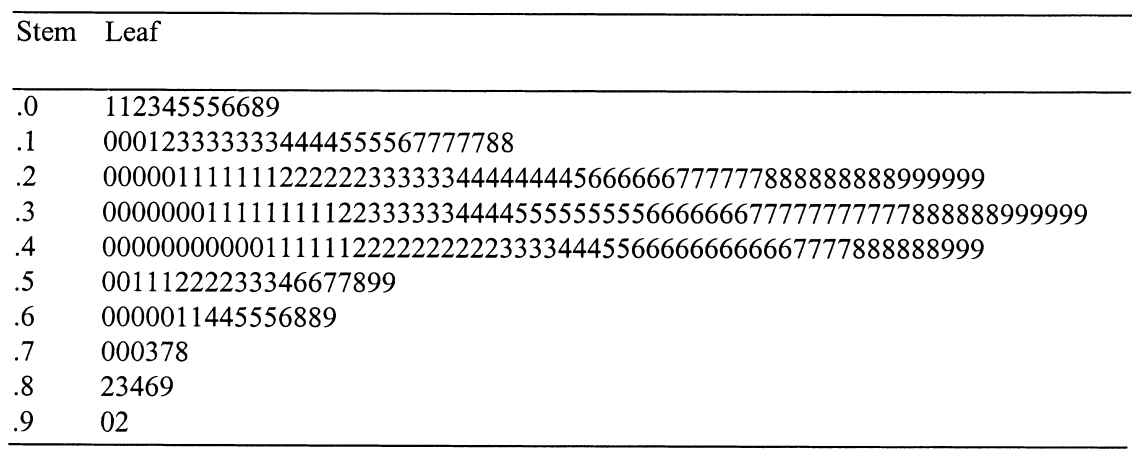

Fig. 1. Stem-and-leaf plot of the 278 retrieved effect sizes.

Table 3

Results of parametric adjustability analysis

\begin{tabular}{lcc}
\hline Moderator & $b(\mathrm{SE})$ & $p^{\mathrm{a}}$ \\
\hline Quality & $0.073(0.037)$ & 0.03 \\
Intentions & $-0.020(0.037)$ & 0.30 \\
Product type & $0.067(0.100)$ & 0.25 \\
Hybrids & $0.023(0.042)$ & 0.59 \\
Development & $0.194(0.035)$ & $<0.001$ \\
No. of cues & $-0.274(0.040)$ & $<0.001$ \\
Design & $-0.078(0.033)$ & 0.01 \\
Sample type & $-0.003(0.039)$ & 0.94 \\
Intercept & $0.358(0.122)$ & $<0.001$ \\
Model fit: & $N=278$ & \\
& $R^{2}=0.438$ & \\
& $F_{\text {model }}[19,258]=10.58$ & \\
\hline
\end{tabular}

a One-sided, except for "hybrids" and "sample type".

H1 posits that the effect of country of origin is largest for perceived quality, and smallest for purchase intentions, with attitude judgments falling in between. In line with this hypothesis, we find that the country-of-origin effect is larger for quality judgments than for attitudes $(b=0.073, p=0.03)$ and purchase intentions $(b=0.093, p=0.02)$. However, no significant difference is found between the effect sizes for attitudes and purchase intentions, although the difference is in the expected direction $(b=-0.02, p=0.30)$. Thus, $\mathrm{H} 1$ is partially supported.

With regard to the product-related moderators, we found that the countryof-origin effect is not significantly larger for consumer goods than for in- 
dustrial goods (H2). However, the observed difference is in the expected direction $(b=0.067, p=0.25)$. No significant difference was found between the effect sizes for hybrid and non-hybrid products, which rejects $\mathrm{H} 3(b=0.023$, $p=0.59)$. H4 states that the country-of-origin effect is larger when subjects are asked to compare products from MDCs with products from LDCs, instead of products from either MDCs or LDCs among themselves. This hypothesis is supported $(b=0.194, p<0.001)$.

In addition to these product-related moderators, we examined the role of a number of moderators that relate to research design. In line with H5, it was found that country-of-origin effects are smaller for multi-cue studies than for single-cue studies $(b=-0.274, p<0.001)$. Further, it was found that betweensubjects designs yield smaller effect sizes than within-subjects designs ( $b=-0.078, p=0.01)$, which is consistent with H6. H7 states that country-oforigin effect sizes do not differ between studies that use student samples and studies that use "representative" consumer samples. Our analyses show that this is indeed the case $(b=-0.003, p=0.94)$.

\section{Discussion}

Country-of-origin effects are a complex phenomenon. In our review, we have distinguished between cognitive, affect and normative aspects of country of origin. The boundaries between these aspects are fuzzy, and country-oforigin effects are often caused by an interplay of cognitive, affective and normative aspects. Cognitively, country of origin may be regarded as an extrinsic cue for product quality. Consumers have been found to infer judgments of product quality from product-country images, which contain beliefs about a country's products, but also about more general characteristics, like its economy, workforce and culture. Symbolic and emotional associations with country of origin constitute the affective aspect. Consumers relate country of origin to status, identity, national pride and past experiences. Normative aspects of country of origin relate to "customer voting". The decision to purchase or avoid a country's products can be regarded as a vote pro or contra the policies and practices of the country. A particularly salient norm is the norm to buy domestic. Consumer ethnocentrism (Shimp \& Sharma, 1987) has been found to have a substantial impact on the purchasing behavior of many consumers.

We have sought to quantify the findings of past country-of-origin research in a meta-analysis. Based on the grand average effect size of 0.39 found in our 
meta-analysis, the country-of-origin effect can be classified as a substantial factor in product evaluations. We found that the impact of country of origin is stronger for perceived quality than for attitudes and purchase likelihood. Apparently, there exists a particularly strong link between country of origin and perceived quality. One factor that is closely related to the evaluation of products in general is the level of development of the country of origin. We found that country-of-origin effects are significantly larger when products from MDCs are compared with products from LDCs. This finding supports the notion that consumers believe that products from LDCs are lower in quality, and associated with a larger risk of bad performance and dissatisfaction (cf., Cordell, 1991).

We also looked at other substantial issues. We found that country-of-origin effects are not significantly smaller for industrial goods than for consumer goods. Although industrial buyers are generally held to be more "rational" and better informed than the average consumer (Webster \& Wind, 1972), the effects of country of origin on purchase decisions for industrial and consumer goods seem to be comparable in magnitude. Furthermore, it is found that the effect of country of origin does not change substantially when a product is designed and manufactured in different countries. Thus, the growing importance of multi-national production and international sourcing (Yip, 1995), which has been viewed by some as the end of the country-of-origin effect, does not seem to affect the relevance of country of origin. As noted by Chao (1998), consumers may often be unaware or indifferent about the actual place of manufacture, and rely on brand origin (i.e., the location of company headquarters). An interesting aspect of multi-national production is the opportunity to pragmatically emphasize those "origin countries" that carry favorable connotations. An example of this strategy is provided by the Spanish "Seat" cars, that highlights the German origin of its engines and other components.

We have also investigated several methodological issues in country-oforigin research. Our meta-analysis shows that methodology can have a substantial impact on study findings. Our analysis corroborates two common propositions. First, single-cue studies yield larger effect sizes than multi-cue studies. Hence, our study adds to a larger body of meta-analytic evidence (e.g., Rao \& Monroe, 1989), that indicates that single-cue studies should be interpreted with caution. Second, we found that effect sizes obtained with a between-subjects design are smaller than those obtained with a within-subjects design.

Further, we found that effect sizes do not differ between student and nonstudent samples. It should be noted, however, that this finding does not imply 
that country-of-origin effects are similar for students and for consumers in general. Meta-analysis does not allow us to draw conclusions on underlying mechanisms, but is concerned with the mere size of the country-of-origin effect.

The parametric adjustability model allows us to calculate the expected effect size for a particular study, by inserting the appropriate value for each parameter. Such calculations provide country-of-origin researchers with a benchmark for the interpretation of outcomes of future studies (Farley et al., 1995). Expected effect sizes can also be used as input for power analysis, allowing researchers to make an a priori estimate of the sample size that is needed to achieve the desired statistical power (cf., Cohen, 1988).

It should be noted that meta-analysis is limited by the design and execution of the studies it includes. Country-of-origin effects have typically been studied in surveys or experiments that either manipulate country of origin or ask consumers to evaluate products from a number of countries. In both instances, consumers are provided with (mostly verbal) product descriptions. Rating scales are used to measure judgments of a number of product attributes. Such an approach fosters a cognitive trade-off of cues and is ill-suited for the study of affective and normative aspects of consumer decision making (e.g., Esses, Haddock \& Zanna, 1993). Hence, our meta-analysis of countryof-origin effects does not fully capture all aspects of country of origin that have been discussed.

Our study provides several avenues for future research. It seems important to recognize the fact that country of origin is not "just another" quality cue, but that its effects on consumer behavior are based on a wider range of connotations, including affective and normative dimensions. In this light, it may be valuable to design studies in which the cognitive, affective and normative influences of country of origin are explicitly modeled and their (possibly contradictory) influences are disentangled. It is likely that such research cannot suffice with the methods that have been typically applied in past research on country-of-origin effects. The framework that has been developed by Askegaard and Ger $(1996,1998)$ offers some useful suggestions for other approaches.

The findings concerning economic development underline the importance of competitive context. The study of the impact of competitive context may be broadened by examining the role of culture, technological development and natural resources. Economic development alone cannot explain why consumers have a preference for French wine, German cars, Italian clothes, and Japanese electronics. Moreover, it should be realized that competitive 
context changes over time, as demonstrated by e.g., the rise of Japanese manufacturers of cars and consumer electronics, and the more recent emergence of companies from other Asian countries like Korea and Singapore. The global diffusion of production technology, as described by Vernon's (1966) international product life cycle theory, enables developing countries to establish their own competitive position in the global market. As a result, consumers get used to the idea that computers are manufactured in Taiwan and running shoes are made in China or India. A more thorough consideration of the processes that underlie such developments could provide us with valuable new insights into the backgrounds of consumers' product-country images.

\section{Acknowledgements}

The authors would like to thank the associate editors, Russell W. Belk and Henry S.J. Robben, and two anonymous reviewers for their valuable comments.

\section{Appendix A. Country-of-origin studies used in the meta-analysis}

Ahmed, S. A., \& d'Astous, A. (1993). Cross-national evaluation of made-in concept using multiple cues. European Journal of Marketing, 27 (7), 39-52.

Alden, D. L., Hoyer, W. D., \& Crowley, A. E. (1993). Country-of-origin cues, perceived risk and evaluation strategy. Advances in Consumer Research, 20, 678-683.

Chakraborty, G., Allred, A. T., \& Bristol, T. (1996). Exploring consumers' evaluations of counterfeits: The roles of country of origin and ethnocentrism. Advances in Consumer Research, 23, 379-384.

Chao, P. (1989). Export and reverse investment: Strategic implications for newly industrialized countries. Journal of International Business Studies, 20 (1), 75-91.

Chao, P. (1993). Partitioning country-of-origin effects: Consumer evaluations of a hybrid product. Journal of International Business Studies, 24 (2), 291306.

Cordell, V. V. (1991). Competitive context and price as moderators of country-of-origin preferences. Journal of the Academy of Marketing Science, 19 (2), 123-128. 
Cordell, V. V. (1992). Effects of consumer preferences for foreign sourced products. Journal of International Business Studies, 23 (2), 251-269.

Cossé, T. J., Lascu, D. N., \& Weisenberger, T. M. (1995). Country-of-manufacture and country of origin: Stereotyping effects when product make is not salient. Proceedings of the 24th EMAC Conference (pp. 1515-1523).

Darling, J. R. (1987). A longitudinal analysis of the competitive profile of products and associated marketing practices of selected european and noneuropean countries. European Journal of Marketing, 21 (3), 17-29.

Erickson, G. M., Johansson, J. K., \& Chao, P. (1984). Image variables in multi-attribute product evaluations: Country-of-origin effects. Journal of Consumer Research, 11, 694-699.

Ettenson, R., Kuznetzov, A., \& Vetrova, E. (1992). Consumer decision making in the soviet union: A conjoint analysis of brand name and country-of-origin effects. Proceedings of the 21st EMAC Conference (pp. 363-380).

Ettenson, R., \& Wagner, J. (1986). Retail buyers' saleability judgments: A comparison of information use across three levels of experience. Journal of Retailing, 62 (1), 41-63.

Ettenson, R., Wagner, J., \& Gaeth, G. (1988). Evaluating the effect of country of origin and the "made in the U.S.A." campaign: A conjoint approach. Journal of Retailing, 64 (1), 85-100.

Han, C. Min, \& Terpstra, V. (1988). Country-of-origin effects for uni-national and bi-national products. Journal of International Business Studies, 19 (2), 235-255

Han, C. Min, Lee, B.-W., \& Ro, K.-K. (1994). The choice of a survey mode in country image studies. Journal of Business Research, 29, 151-162.

Hisrich, R. D., Peters, M. P., \& Weinstein, A. K. (1981). East-West trade: The view from the United States. Journal of International Business Studies, 12 (3), 109-121.

Hong, S. -T., \& Wyer Jr., R. S. (1990). Determinants of product evaluation: Effects of the time interval between knowledge of a product's country of origin and information about its specific attributes. Journal of Consumer Research, 17, 277-288.

Johansson, J. K., \& Nebenzahl, I. D. (1986). Multinational production: Effect on brand value. Journal of International Business Studies, 17 (3), 101126.

Johansson, J. K., Ronkainen, I. A., \& Czinkota M. R. (1994). Negative country-of-origin effects: The case of the new Russia. Journal of International Business Studies, 25 (1), 157-176. 
Jun W.-J., \& Jolibert, A. J. P. (1983). Revealed vs. hidden attributes as determinants of perceived product quality. Journal of Economic Psychology, 4, 263-272.

Kaynak, E., \& Kucukemiroglu, O. (1992). Sourcing of industrial products: Regiocentric orientation of Chinese organizational buyers. European Journal of Marketing, 26 (5), 36-55.

Klenosky, D. B., Benet, S. B., \& Chadraba, P. (1996). Assessing Czech consumers' reactions to western marketing practices: A conjoint approach. Journal of Business Research, 36, 189-198.

Lambert, D. R. (1981). Price as a quality cue in industrial buying. Journal of the Academy of Marketing Science, 9 (3), 227-238.

Lantz, G., \& Loeb, S. (1996). Country of origin and ethnocentrism: An analysis of Canadian and American preferences using social identity theory. Advances in Consumer Research, 23, 374-378.

Lee, D. J., \& Brinberg, D. (1995). The effect of the perception of process technology and country-of-manufacture favorableness on consumers' overall brand evaluation. Advances in Consumer Research, 22, 286-291.

Levin, I. P., Jasper, J. D., Mittelstaedt, J. D., \& Gaeth, G. J. (1993). Attitudes toward 'Buy American First' and preferences for American and Japanese cars: A different role for country-of-origin information. Advances in Consumer Research, 20, 625-629.

Li, W.-K., Leung, K., \& Wyer Jr., R. S. (1993). The roles of country-of-origin information on buyers' product evaluations: Signal or attribute? Advances in Consumer Research, 20, 684-689.

Li, W.-K., Monroe, K. B., \& Chan, D. K. -S. (1994). The effects of country of origin, brand and price information: A cognitive-affective model of buying intentions. Advances in Consumer Research, 21, 449-457.

Li, W.-K., \& Wyer Jr., R. S. (1994). The role of country of origin in product evaluations: informational and standard-of-comparison effects. Journal of Consumer Psychology, 3, 187-212.

Lim, J.-S., Darley, W. K., \& Summers, J. O. (1994). An assessment of country of origin effects under alternative presentation formats. Journal of the Academy of Marketing Science, 22 (3), 274-282.

Lin, L.-W., \& Sternquist, B. (1994). Taiwanese consumers' perceptions of product information cues: Country of origin and store prestige. European Journal of Marketing, 28 (1), 5-18.

Maheswaran, D. (1994). Country of origin as a stereotype: Effects of consumer expertise and attribute strength on product evaluations. Journal of Consumer Research, 21, 354-365. 
Marcoux, J.-S., Filiatrault, P., \& Cheron, E. J. (1995). The attitudes underlying Polish consumers preferences toward products made in Western countries. Proceedings of the 24th EMAC Conference (pp. 669-681).

Merritt, S., \& Stauble, V. (1995). A cross-cultural exploration of country-oforigin preference. Proceedings of the 1995 AMA Winter Educators' Conference (pp. 380-386).

Mittal, V., \& Tsiros, M. (1995). Does country of origin transfer between brands? Advances in Consumer Research, 22, 292-296.

Niffenegger, P., White, J., \& Marmet, G. (1982). How european retailers view American imported products: Results of a product image survey. Journal of the Academy of Marketing Science, 10 (3), 281-291.

Pecotich, A., Pressley, M., \& Roth, D. (1993). The impact of ethnocentrism on the country-of-origin effect in the service sector. Proceedings of the 22nd EMAC Conference (pp. 1245-1266).

Stoltman, J. J., Lim, Y. K., \& Morgan, F. W. (1991). The effect of country of origin, product familiarity, \& ethnocentrism on the acceptance of foreign products. Proceedings of the 1991 AMA Winter Educators' Conference (pp. 82-89).

Wall, M., Liefield, J., \& Heslop, L. A. (1991). Impact of country-of-origin cues on consumer judgments in multi-cue situation: A covariance analysis. Journal of the Academy of Marketing Science, 19 (2), 105-113.

Wang, C. K., \& Lamb Jr., C. W. (1980). Foreign environmental factors influencing American consumers' predispositions toward European products. Journal of the Academy of Marketing Science, 8, 345-356.

Zhang, Y. (1996). Chinese consumers' evaluation of foreign products: The influence of culture, product types and product presentation format. $\mathrm{Eu}$ ropean Journal of Marketing, 30 (12), 50-68.

\section{References}

Ahmed, S. A., \& d'Astous, A. (1995). Comparison of country-of-origin effects on household and organizational buyers' product perceptions. European Journal of Marketing, 29 (3), 35-51.

Anderson, E., \& Weitz, B. (1989). Determinants of continuity in conventional industrial channel dyads. Marketing Science, 8, 310-323.

Arnould, E. J. (1989). Toward a broadened theory of preference formation and the diffusion of innovations: Cases from Zinder province, Niger Republic. Journal of Consumer Research, 16, $239-267$.

Askegaard, S., \& Ger, G. (1996). Product-country images as stereotypes: A comparative study. Proceedings of the 21st Annual Colloquium of the I.A.R.E.P. (pp. 13-28).

Askegaard, S., \& Ger, G. (1998). Product-country images: Toward a contextualized approach. European Advances in Consumer Research, forthcoming. 
Bass, F.M., \& Wind, J. (1995). Introduction to the special issue: Empirical generalizations in marketing. Marketing Science, 14 (3, part 2), G36-G46.

Batra, R., Ramaswamy, Alden, D.L., Steenkamp, J.-B.E.M., \& Ramachander, S. (1999). Effects of brand local/non-local origin on consumer attitudes in developing countries. Journal of Consumer Psychology, forthcoming.

Bilkey, W. J., \& Nes, E. (1982). Country-of-origin effects on product evaluations. Journal of International Business Studies, 13 (1), 89-99.

Botschen, G., \& Hemettsberger, A. (1998). Diagnosing means-end structures to determine the degree of potential marketing program standardization. Journal of Business Research, 42, 151-159.

Broniarczyk, S. M., \& Alba, J. W. (1994). The role of consumers' intentions in inference making. Journal of Consumer Research, 21, 393-407.

Chao, P. (1993). Partitioning country-of-origin effects: Consumer evaluations of a hybrid product. Journal of International Business Studies, 24, 291-306.

Chao, P. (1998). Impact of country-of-origin dimensions on product quality and design quality perceptions. Journal of Business Research, 42, 1-6.

Cohen, J. (1988). Statistical power analysis for the behavioral sciences. Hillsdale, NJ: Erlbaum.

Cohen, J. B., \& Areni, C. S. (1991). Affect and consumer behavior. In: T. S. Robertson, \& H. H. Kassarjian, Handbook of consumer behavior (p. 188-240). Englewood Cliffs, NJ: Prentice-Hall.

Cordell, V. V. (1991). Competitive context and price as moderators of country-of-origin preferences. Journal of the Academy of Marketing Science, 19 (2), 123-128.

Dawar, N., \& Parker, P. (1994). Marketing universals: Consumers' evaluations use of brand name price physical appearance and retailer reputation as signals of product quality. Journal of Marketing, 58, 81-95.

Dichter, E. (1962). The world customer. Harvard Business Review, 40 (4), 113-122.

Esses, V. M., Haddock, G., \& Zanna, M. P. (1993). Values, stereotypes, and emotions as determinants of intergroup attitudes. In: D. M. Mackie, \& D. L. Hamilton, Affect, cognition, and stereotyping: Interactive processes in group perception. San Diego, CA: Academic Press.

Farley, J. U., \& Lehmann, D. R. (1994). Cross-national laws and differences in market response. Management Science, 40, 111-122.

Farley, J. U., Lehmann, D. R., \& Sawyer, A. (1995). Empirical marketing generalizations using metaanalysis. Marketing Science, 14 (3, part 2), G36-G46.

Fern, E. F., \& Monroe, K. B. (1996). Effect-size estimates: Issues and problems in interpretation. Journal of Consumer Research, 23, 89-105.

Fournier, S. (1998). Consumers and their brands: Developing relationship theory in consumer research. Journal of Consumer Research, 24, 343-373.

Friedman, M. (1996). A positive approach to organized consumer action: The "buycott" as an alternative to the boycott. Journal of Consumer Policy, 19, 439-451.

Ger, G. (1991). Country image: Perceptions, attitudes, associations, and their relationships to context. Proceedings of the 3rd International Conference on Marketing and Development (pp. 390-398).

Ger, G., Belk, R. W., \& Lascu, D. N. (1993). The development of consumer desire in marketing and developing economies: The cases of Romania and Turkey. Advances in Consumer Research, 20, 102107.

Hedges, L. V., \& Olkin, I. (1985). Statistical methods for meta-analysis. Orlando, FL: Academic Press.

Hirschman, E. C. (1985). Primitive aspects of consumption in modern American society. Journal of Consumer Research, 12, 142-154.

Hoffman, M. L. (1986). Affect, cognition and motivation. In: R. M. Sorrentino, \& C. T. Higgins, Handbook of motivation and cognition: Foundations of social behavior (Vol. 1). New York: Guilford Press.

Holbrook, M. B., \& Corfman, K. (1985). Quality and value in the consumption experience: Phaedrus rides again. In: J. Jacoby, \& J. C. Olson, Perceived quality: How consumers view stores and merchandise. Lexington, MA: Lexington Books. 
Hong, S.-T., \& Wyer, Jr., R. S. (1989). Effects of country of origin and product-attribute information on product evaluation: An information processing perspective. Journal of Consumer Research, 16, 175187.

Hong, S.-T., \& Wyer, Jr., R. S. (1990). Determinants of product evaluation: Effects of the time interval between knowledge of a product's country of origin and information about its specific attributes. Journal of Consumer Research, 17, 277-288.

Isen, A. M. (1984). Toward understanding the role of affect in cognition. In: Wyer Jr., R. S., \& T. K. Srull, Handbook of social cognition (Vol. 1). Hillsdale, NJ: Erlbaum.

Johnston, J. (1984). Econometric methods. Singapore: McGraw-Hill.

Klein, J. G., Ettenson, R., \& Morris, M. D. (1998). The animosity model of foreign product purchase: An empirical test in the People's Republic of China. Journal of Marketing, 62 (1), 89-100.

Leclerc, F., Schmitt, B. H., \& Dubé, L. (1994). Foreign branding and its effects on product perceptions and attitudes. Journal of Marketing Research, 31, 263-271.

Lefkoff-Hagius, R., \& Mason, C. H. (1993). Characteristic, beneficial, and image attributes in consumer judgments of similarity and preference. Journal of Consumer Research, 20, 100-110.

Li, W.-K., Monroe, K. B. (1992). The role of country-of-origin information on buyers' product evaluation: An in-depth interview approach. Proceedings of the 1992 AMA Summer Educators' Conference (pp. 274-280).

Li, W.-K., \& Wyer, Jr., R. S. (1994). The role of country of origin in product evaluations: Informational and standard-of-comparison effects. Journal of Consumer Psychology, 3, 187-212.

Mittal, B., Ratchford, B., \& Prabhakar, P. (1990). Functional and expressive attributes as determinants of brand-attitude. Research in Marketing, 10, 135-155.

Obermiller, C. (1993). Comments of evolving country-of-origin research. Advances in Consumer Research, 20, 690-691.

Obermiller, C., \& Spangenberg, E. (1989). Exploring the effects of country-of-origin labels: An information processing framework. Advances in Consumer Research, 16, 454-459.

Olson, J. C. (1972). Cue utilization of the quality perception process: A cognitive model and an empirical test. Doctoral dissertation. Durham, NC: Purdue University.

Osterhus, T. L. (1997). Pro-social consumer influence strategies: When and how do they work?. Journal of Marketing, 61, 16-29.

Papadopoulos, N., Heslop, L. A. (1993). Product-country images: Impact and role in international marketing. New York: Hayworth Press.

Peterson, R. A., \& Jolibert, A. J. P. (1995). A meta-analysis of country-of-origin effects. Journal of International Business Studies, 26, 883-900.

Pinson, C. (1986). An implicit product theory approach to consumers' inferential judgments about the products. International Journal of Research in Marketing, 3, 19-38.

Porter, M. E. (1990). The competitive advantage of nations. London: MacMillan.

Rao, A. R., \& Monroe, K. B. (1989). The effect of price, brand name, and store name on buyers' perceptions of product quality: An integrative review. Journal of Marketing Research, 26, 351-357.

Roth, M. S., \& Romeo, J. B. (1992). Matching product category and country image perceptions: A framework for managing country-of-origin effects. Journal of International Business Studies, 23, 477497.

Schooler, R. D. (1965). Product bias in the Central American common market. Journal of Marketing Research, 2, 394-397.

Schwartz, S. H. (1973). Normative explanations of helping behavior: A critique, proposal and empirical test. Journal of Experimental Social Psychology, 9, 349-364.

Sharma, S., Shimp, T. A., \& Shin, J. (1995). Consumer ethnocentrism: A test of antecedents and moderators. Journal of the Academy of Marketing Science, 23, 26-37.

Shimp, T. A., \& Sharma, S. (1987). Consumer ethnocentrism: Construction and validation of the CETSCALE. Journal of Marketing Research, 24, 280-289. 
546 P.W.J. Verlegh, J.-B.E.M. Steenkamp / Journal of Economic Psychology 20 (1999) 521-546

Smith, N. (1990). Morality and the market. London: Routledge.

Steenkamp, J. -B. E. M. (1989). Product quality. Van Gorcum, Assen (NL).

Steenkamp, J. -B. E. M. (1990). Conceptual model of the quality perception process. Journal of Business Research, 21, 309-333.

Sternthal, B., Tybout, A. M., \& Calder, B. J. (1994). Experimental design: Generalization and theoretical explanation. In: Bagozzi, R. P., Principles of marketing research. Cambridge: Blackwell.

Usunier, J. -C. (1996). Marketing across cultures. London: Prentice-Hall.

Vernon, R. (1966). International investment and international trade in the product cycle. Quarterly Journal of Economics, 80, 190-207.

Webster, Jr. F., \& Wind, Y. (1972). A general model for understanding organizational buying behavior. Journal of Marketing, 36, 12-19.

Yip, G. S. (1995). Total global strategy: Managing for worldwide competitive advantage. Englewood Cliffs, NJ: Prentice-Hall. 